\title{
Long-term morbidity and mortality in patients without early complications after stroke or transient ischemic attack
}

\author{
Jodi D. Edwards PhD, Moira K. Kapral MD, Jiming Fang PhD, Richard H. Swartz MD PhD
}

Cite as: CMAJ 2017 July 24;189:E954-61. doi: 10.1503/cmaj.161142

See related article www.cmaj.ca/lookup/doi/10.1503/cmaj.170410

Visual abstract available at www.cmaj.ca/lookup/suppl/doi:10.1503/cmaj.161142/-/DC2

\begin{abstract}
BACKGROUND: Secondary prevention after stroke and transient ischemic attack (TIA) has focused on high early risk of recurrence, but survivors of stroke can have substantial long-term morbidity and mortality. We quantified long-term morbidity and mortality for patients who had no early complications after stroke or TIA and community-based controls.
\end{abstract}

METHODS: This longitudinal casecontrol study included all ambulatory or hospitalized patients with stroke or TIA (discharged from regional stroke centres in Ontario from 2003 to 2013) who survived for 90 days without recurrent stroke, myocardial infarction, all-cause admission to hospital, admission to an institution or death. Cases and controls were matched on age, sex and geo- graphic location. The primary composite outcome was death, stroke, myocardial infarction, or admission to long-term or continuing care. We calculated 1-, 3- and 5-year rates of composite and individual outcomes and used cause-specific Cox regression to estimate long-term hazards for cases versus controls and for patients with stroke versus those with TIA.

RESULTS: Among patients who were initially stable after stroke or TIA ( $n=$ 26366), the hazard of the primary outcome was more than double at 1 year (hazard ratio [HR] 2.4, 95\% confidence interval $[\mathrm{Cl}] 2.3-2.5$ ), 3 years (HR 2.2, $95 \% \mathrm{Cl} 2.1-2.3$ ) and 5 years (HR 2.1, $95 \% \mathrm{Cl}$ 2.1-2.2). Hazard was highest for recurrent stroke at 1 year $(\mathrm{HR} 6.8,95 \% \mathrm{Cl}$
6.1-7.5), continuing to 5 years (HR 5.1, $95 \% \mathrm{Cl} 4.8-5.5)$, and for admission to an institution (HR 2.1, 95\% Cl 1.9-2.2). Survivors of stroke had higher mortality and morbidity, but $31.5 \%$ (1789/5677) of patients with TIA experienced an adverse event within 5 years.

INTERPRETATION: Patients who survive stroke or TIA without early complications are typically discharged from secondary stroke prevention services. However, these patients remain at substantial long-term risk, particularly for recurrent stroke and admission to an institution. Novel approaches to prevention, potentially embedded in community or primary care, are required for long-term management of these initially stable but high-risk patients.
M

uch of the risk of recurrent stroke accrues early after the index event, ${ }^{1-3}$ with population-based estimates ranging from $3.2 \%$ to $18.5 \%$ at 90 days after stroke ${ }^{4}$ and $0.6 \%$ to $16.8 \%$ at 90 days after transient ischemic attack (TIA). ${ }^{5}$ The short-term risk of myocardial infarction is lower, ranging from $0.5 \%$ to $4.7 \%$ at 1 year, with a cumulative absolute risk of about $2 \%$ per year. ${ }^{6}$ Because of these high rates of early recurrence, the 90-day period after stroke or TIA has been a major focus of secondary prevention in both research and clinical practice. ${ }^{7-9}$

In addition to high short-term risks, population-based studies have shown that the risk of recurrent vascular events and death after stroke and TIA can remain elevated over the long term, with 5- and 10-year estimates approximating 18\% and $44 \%$, respectively. ${ }^{10-14}$ However, in most of these studies, risk estimates have included those with adverse outcomes in the early high-risk period, and few data have been available to characterize long-term risk in survivors who had no early complications after stroke or TIA. The purpose of this study was to determine the long-term risks of morbidity and mortality among survivors of ischemic stroke or TIA who did not experience any adverse complications in the first 90 days after discharge, relative to matched controls. 


\section{Methods}

We used administrative health data from the province of Ontario, Canada, to perform a longitudinal, retrospective matched casecontrol registry study.

\section{Data sources}

We obtained Ontario Stroke Registry data from the Institute for Clinical Evaluative Sciences. The Ontario Stroke Registry, authorized under provincial privacy legislation to perform data collection without individual patient consent, used active ascertainment methods to capture all consecutive patients with acute stroke or TIA presenting to the emergency department or admitted to hospital in 12 regional stroke centres in Ontario. Data entry was completed by trained abstractors, and reliability testing showed excellent agreement (100\%) for key variables. ${ }^{15}$ We linked the Ontario Stroke Registry with provincial databases using unique encoded patient identifiers to obtain longitudinal data for the identification of matched controls and assessment of study outcomes.

We used the Canadian Institute for Health Information Discharge Abstract Database, which maintains a high level of consistency for the selection and coding of the most responsible diagnosis, ${ }^{16}$ to document emergency department visits and hospital admissions for all study outcomes, according to the International Statistical Classification of Diseases and Related Health Problems, 10th revision (Appendix 1, available at www.cmaj.ca/lookup/suppl/doi:10.1503/cmaj.161142/-/DC1). We obtained matched controls and data on out-of-hospital deaths from the Ontario Registered Persons Database. We used the Continuing Care Reporting System, which uses an internationally validated assessment instrument as its clinical data standard, ${ }^{17}$ to capture admissions to long-term and continuing care as a proxy of functional status or disability after stroke or TIA.

\section{Cases}

All consecutive patients with ischemic stroke or TIA seen in the emergency department or discharged from hospital at regional stroke centres in the province of Ontario from July 1 , 2003, to Mar. 31, 2013, were identified from the Ontario Stroke Registry. To identify a cohort of initially stable patients, we then restricted the cases to patients who did not experience any of the following within 90 days after discharge: death; admission to hospital for stroke, TIA, myocardial infarction or any other cause; or admission to a long-term or complex continuing care facility.

\section{Matched controls}

Controls were identified from the general Ontario population for the period 2003 to 2013 and were matched to cases, at a 10:1 ratio, on key confounding demographic health indicators, including age $( \pm 1 \mathrm{yr}$ ), sex, income quintile and area of residence. To ensure a similar length and period of follow-up, we also matched the cases and controls on the date of the case entry event ( $\pm 50 \mathrm{~d}$ ), and we followed selected controls for 1,3 and 5 years from 90 days after the case discharge date to the occurrence of an outcome event or censoring at the end of each follow-up period. To ensure a representative primary prevention control population, we included those with at least one medical contact during the study period: any emergency department visit or hospital admission; an Ontario Health Insurance Plan claim for a physician visit or diagnostic test; or an Ontario Drug Benefit prescription claim, including those with a history of vascular comorbidities. However, as part of the causal pathway, these comorbidities were not included as matching variables. ${ }^{18}$ Those with a death date before the case index event date $(n=317362)$ or any adverse complication within the first 90 days of the case's index event date $(n=235036)$ were excluded and not considered eligible for matching.

\section{Outcomes}

The primary outcome was a composite measure of mortality and morbidity, encompassing death, hospital admission for recurrent stroke or myocardial infarction, or admission to a long-term or continuing care facility. Cases were compared with controls on the primary outcome at 1, 3 and 5 years from the end of the 90 days after the discharge date for the entry event. Secondary outcomes were individual measures from the composite outcome.

\section{Statistical analyses}

We used descriptive statistics to characterize cases with respect to demographic and clinical variables, as well as medications and interventions (endarterectomy and stenting for stroke prevention), for stroke and TIA combined and separately. Standardized differences in means or proportions were used to compare case-control pairs on matching variables, with significance defined as an absolute value greater than 0.20 (small effect size).

We determined the proportions of cases and controls that experienced the composite and secondary outcomes within 1, 3 or 5 years of discharge after stroke or TIA. We used $\chi^{2}$ testing to compare proportions between cases and matched controls and to compare within the stroke versus TIA patient subgroups.

We generated cause-specific Cox proportional hazards models to estimate 1-, 3- and 5-year hazards for both composite and secondary outcomes. Outcome ascertainment was conducted independently within each follow-up period, such that events occurring in the first year after 90 days postdischarge were not included in 3- or 5-year estimates, and those occurring from the 1-year censoring date to 3 years after 90 days postdischarge were not included in the 5-year estimates. All models were adjusted for death as a competing risk and used robust standard error methods to account for clustering in matched pairs.

\section{Ethics approval}

This study was approved by the Research Ethics Board of Sunnybrook Health Sciences Centre. 


\section{Results}

A total of 38241 patients were discharged after ischemic stroke or TIA from hospital or emergency departments at regional stroke centres from July 1, 2003, to Mar. 31, 2013. Of these, 11681 (30.5\%) experienced an adverse complication within
90 days of discharge and were excluded from the study cohort, which left 26560 patients eligible for matching. A total of 16607857 controls considered eligible for matching were identified from the Ontario Registered Persons Database. Applying a 10:1 matching ratio, we successfully matched $99.3 \%$ of the cases, to yield a total of 26366 cases and 263660 matched controls

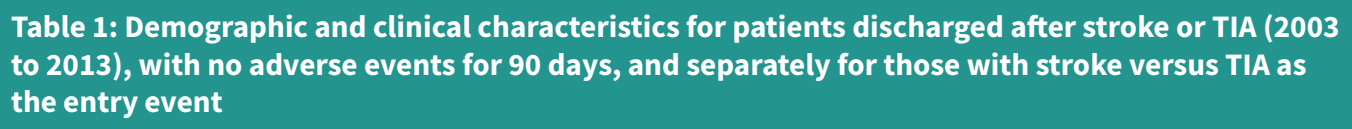

Event type; no. $(\%)$ of patients

\begin{tabular}{|c|c|c|c|c|}
\hline Characteristic & $\begin{array}{c}\text { Stroke or TIA } \\
n=26366\end{array}$ & $\begin{array}{c}\text { Stroke } \\
n=15950\end{array}$ & $\begin{array}{c}\text { TIA } \\
n=10416\end{array}$ & $\begin{array}{l}\text { Standardized } \\
\text { difference* }\end{array}$ \\
\hline Aget, yr, median (IQR) & $72(60-80)$ & $72(60-80)$ & $72(61-81)$ & 0.03 \\
\hline Sex, female & 12360 (46.9) & $7127(44.7)$ & $5233(50.2)$ & 0.11 \\
\hline \multicolumn{5}{|l|}{ Stroke type } \\
\hline Stroke & $15950(60.5)$ & $15950(100.0)$ & - & \\
\hline TIA & $10416(39.5)$ & - & $10416(100.0)$ & - \\
\hline \multicolumn{5}{|l|}{ Clinical comorbidity } \\
\hline Prior stroke & $3715(14.1)$ & $2175(13.6)$ & $1540(14.8)$ & 0.03 \\
\hline Prior acute MI & $2030(7.7)$ & $1334(8.4)$ & $696(6.7)$ & 0.06 \\
\hline Congestitve heart failure & $3563(13.5)$ & $2295(14.4)$ & $1268(12.2)$ & 0.07 \\
\hline Hypertension & $19521(74.0)$ & $12282(77.0)$ & $7239(69.5)$ & 0.17 \\
\hline Diabetes mellitus & $7741(29.4)$ & $5004(31.4)$ & $2737(26.3)$ & 0.11 \\
\hline Hyperlipidemia & $5232(19.8)$ & $2964(18.6)$ & $2268(21.8)$ & 0.08 \\
\hline Atrial fibrillation & $4591(17.4)$ & $3254(20.4)$ & $1337(12.8)$ & 0.20 \\
\hline \multicolumn{5}{|c|}{ Canadian Neurological Scale Group $\dagger^{19}$} \\
\hline Mild ( $\geq 8)$ & $22364(86.3)$ & $12355(78.6)$ & $10009(98.1)$ & 0.64 \\
\hline Moderate (5-7) & $2531(9.8)$ & $2374(15.1)$ & $157(1.5)$ & 0.51 \\
\hline Severe (0-4) & $1021(3.9)$ & $983(6.3)$ & $38(0.4)$ & 0.33 \\
\hline Admission to registry hospital & $15901(60.3)$ & $13153(82.5)$ & $2748(26.4)$ & 1.36 \\
\hline tPA on admission & $2275(8.6)$ & $2255(14.1)$ & $20(0.2)$ & 0.56 \\
\hline \multicolumn{5}{|l|}{ Discharge medications } \\
\hline Antiplatelet agents & $21348(81.0)$ & 12907 (80.9) & $8441(81.0)$ & 0.01 \\
\hline Warfarin & $4238(16.1)$ & $3157(19.8)$ & $1081(10.4)$ & 0.27 \\
\hline All anticoagulants & $5422(20.6)$ & $4215(26.4)$ & $1207(11.6)$ & 0.39 \\
\hline Antithrombotics & $24192(91.8)$ & $14983(93.9)$ & $9209(88.4)$ & 0.20 \\
\hline \multicolumn{5}{|l|}{ CEA or CAS $\ddagger$} \\
\hline At $1 \mathrm{yr}$ & $229(0.9)$ & $137(0.9)$ & $92(0.9)$ & 0.01 \\
\hline At $3 \mathrm{yr}$ & $278(1.3)$ & $170(1.3)$ & $108(1.3)$ & 0.01 \\
\hline At $5 \mathrm{yr}$ & 239 (1.5) & $138(1.4)$ & $101(1.8)$ & 0.01 \\
\hline
\end{tabular}

Note: $\mathrm{CAS}=$ carotid artery stenting, $\mathrm{CEA}=$ carotid endarterectomy, $\mathrm{IQR}=$ interquartile range, $\mathrm{MI}=$ myocardial infarction, $\mathrm{TI} \mathrm{A}=$ transient ischemic attack, tPA = tissue plasminogen activator.

*The standardized difference, used for subgroup comparisons, is the difference in means or proportions for matched pairs divided by the standard error; an imbalance was defined as an absolute value greater than 0.20 (small effect size).

†For this characteristic, complete data were available for 25916 of the patients: 15712 in the group with stroke and 10204 in the group with TIA $\ddagger$ The percentages for longitudinal analyses are based on the denominator of subcohorts with complete 1-, 3- or 5-year follow-up. The denominator at 1 year was the same as the full cohort: 26366 total ( 15950 with stroke and 10416 with TIA). At 3 years, the subcohort denominator was 21548 total (13287 with stroke and 8261 with TIA), and at 5 years the subcohort denominator was 15571 total (9894 with stroke and 5677 with TIA). 
(Table 1 and Table 2). For the majority of cases, stroke was the entry event ( $n=15950$ [60.5\%]), with admission to the registry hospital. There was a high burden of cardiovascular comorbidity among the cases, with high prevalence of hypertension ( $n=$ $19521[74.0 \%])$, prior stroke $(n=3715[14.1 \%])$ and diabetes mellitus ( $n=7741[29.4 \%])$.

The proportion of patients with 90-day event-free survival after stroke or TIA who subsequently experienced an adverse event in the primary composite outcome (death, hospital admission for recurrent stroke or myocardial infarction, or admission to long-term or continuing care) was 9.5\% (95\% confidence interval $[\mathrm{Cl}] 9.4 \%-9.6 \%)$ at 1 year, $23.6 \%(95 \% \mathrm{Cl}$ $23.5 \%-23.7 \%)$ at 3 years and $35.7 \%(95 \% \mathrm{Cl} 35.6 \%-35.8 \%)$ at 5 years. For all outcomes, the rate of adverse events at 1, 3 and 5 years was significantly higher among patients with stroke or TIA than among matched controls (Table 3).

There was a doubling of the hazard of the primary outcome (death, hospital admission for stroke or myocardial infarction, or admission to a long-term or continuing care facility) for cases relative to matched controls at 1 year, both for all patients (hazard ratio $[\mathrm{HR}] 2.4,95 \% \mathrm{Cl} 2.3-2.5)$ and for stroke and TIA subgroups separately (Table 4$)$. This risk remained consistent at 3 years (HR 2.2, 95\% Cl 2.1-2.3) and 5 years (HR 2.1, 95\% Cl 2.12.2) after the index stroke or TIA. Across all time points, the highest long-term risks were for recurrent stroke at 1 year (HR 6.8, $95 \% \mathrm{Cl} 6.1-7.5$ ), 3 years (HR 5.6, 95\% Cl 5.2-6.0) and 5 years (HR 5.1, 95\% Cl 4.8-5.5), with an 8-fold increase in recurrent stroke hazard at 1 year when only patients with an index stroke were considered (HR 8.2, 95\% Cl 7.3-9.3) (Table 4). The risk of admission to an institution was also increased more than 2-fold for 5 years. The risks of myocardial infarction and death were lower but also remained constant for 5 years (Table 4).

Table 2: Matching characteristics for patients discharged from Ontario registry stroke centres after stroke or TIA, 2003 to 2013

Group; no. (\%) of patients or controls

\begin{tabular}{|c|c|c|}
\hline $\begin{array}{l}\text { Matching } \\
\text { characteristic*}\end{array}$ & $\begin{array}{c}\text { Stroke or TIA } \dagger \\
n=26366\end{array}$ & $\begin{array}{c}\text { Matched controls } \\
\qquad n=263660\end{array}$ \\
\hline Age, yr, median (IQR) & $72(60-80)$ & $72(60-80)$ \\
\hline Sex, female & $12360(46.9)$ & $123600(46.9)$ \\
\hline Rural residence & $2534(9.6)$ & 25340 (9.6) \\
\hline \multicolumn{3}{|l|}{ Income quintile } \\
\hline 1 & $5939(22.5)$ & $59390(22.5)$ \\
\hline 2 & $5306(20.1)$ & $53060(20.1)$ \\
\hline 3 & $4760(18.1)$ & $47600(18.1)$ \\
\hline 4 & 4860 (18.4) & $48600(18.4)$ \\
\hline 5 & 5501 (20.9) & $55010(20.9)$ \\
\hline
\end{tabular}

Note: IQR = interquartile range, $\mathrm{TIA}=$ transient ischemic attack

${ }^{*}$ Matching was successful for $99.3 \%$ of the original 26560 cases identified.

†Patients had no adverse events within the first 90 days after discharge.

$\ddagger$ Controls (10:1 ratio) were from the general population of Ontario.

\section{Interpretation}

Using a whole-population approach, we quantified the hazard of death, recurrent stroke or myocardial infarction, or admission to a care facility among stroke survivors who experienced no complications in the early high-risk period after stroke or TIA. Even for those who were clinically stable after 90 days, the hazard of experiencing an adverse outcome after stroke or TIA was more than double at 1,3 and 5 years of follow-up, compared with matched controls. Notably, long-term risks were highest for recurrent stroke and admission to an institution, whereas myocardial infarction did not present a substantial long-term risk. Furthermore, even among those who presented with TIA and who were clinically stable after the early high-risk period, a high proportion experienced long-term adverse events within 1, 3 and 5 years after discharge. These analyses indicate that survival after both stroke and TIA is a marker of major long-term risk, which merits aggressive attention to risk reduction strategies.

Only one small study $(n=290)$ previously examined longterm outcomes in clinically stable patients. ${ }^{14}$ That study was conducted over the period 1981-1986, before the modern era of organized stroke care and secondary prevention, and was restricted to patients with TIA as an entry event, who were stroke-free after a median of 3.8 years. ${ }^{14}$ Consistent with that earlier study, we found high long-term hazards of adverse outcomes among patients with stroke or TIA at entry; however, the present study also showed that this hazard was not driven purely by early events, but remained significantly elevated for up to 5 years, even among those free of early complications after stroke or TIA. These findings indicate that both stroke and TIA are sentinel events that confer persistent long-term risks of major adverse outcomes and suggest the need for secondary prevention approaches that not only focus on the management of high short-term risks, but also include strategies for long-term outpatient risk reduction, even when no early adverse complications have occurred.

Consistent with the fact that most individuals who experience a stroke are older, the most common secondary outcome observed in the present study was death, with $26 \%$ of patients dying over the 5-year follow-up period. However, the highest cause-specific hazard for these initially stable patients was for recurrent stroke, at almost 7 times that of matched controls within the first year after stroke or TIA, and remaining 5 times greater for up to 5 years. Recurrent stroke was thus the most important potentially modifiable outcome after stroke or TIA, even if recurrence occurred after the early highrisk period.

These findings highlight the need for long-term management of key modifiable risks for clinically stable survivors of stroke or TIA, including control of hypertension, ${ }^{20}$ detection and treatment of atrial fibrillation, ${ }^{21}$ smoking cessation and physical activity. ${ }^{22}$ Although recent evidence has shown a trend toward improvement in these outcomes since 2003, suggesting improved control of cardiovascular risks over this period,,$^{23}$ our 
findings indicate that in the overall stroke population, the prevalence of modifiable risks remains high. ${ }^{9,24,25}$ Long-term aggressive risk factor reduction might be accomplished by leveraging existing resources and community-based programs for exercise and risk factor control, such as cardiac rehabilitation, but tailoring them to stroke populations and following this model for the longer term (i.e., years rather than months after the index event). In addition, recent efforts have focused on identifying alternative risk markers (e.g., depression, obstructive sleep apnea, cognitive impairment) that may go undetected after a stroke or TIA and that may confer additional risk for recurrence, beyond the traditional modifiable vascular risk factors. ${ }^{26}$

The hazard of admission to an institution was also increased almost 3-fold at 1 year, but declined to rates similar to myocardial infarction and death by 5 years after stroke or TIA. Although admission to an institution is a multifactorial and potentially less easily modifiable outcome, stroke and TIA have been recognized as major causes of institutionalization after acute care. ${ }^{27}$ Recurrent strokes are typically more severe than index events ${ }^{28}$ and have been shown to independently predict both disability and admission to an institution, and also to increase the risk of cognitive decline and dementia. ${ }^{29}$ It is thus not surprising that, given the high observed hazard of recurrent stroke, the hazard of institutionalization was also high. These findings have important implications for the provision of rehabilitative and supportive services after stroke or TIA, even for those who initially appear clinically stable, and suggest that outpatient programs resourced to support sustained, long-term functional improvements are required to

Table 3: Primary composite and secondary outcomes at 1, 3 and 5 years of follow-up* $\dagger$

\begin{tabular}{|c|c|c|c|c|}
\hline \multirow[b]{2}{*}{ Outcome } & \multicolumn{2}{|c|}{ Overall; no. (\%) of patients or controls } & \multicolumn{2}{|c|}{ Subgroup; no. (\%) of patients } \\
\hline & $\begin{array}{c}\text { Stroke or TIA } \\
n=26366\end{array}$ & $\begin{array}{c}\text { Matched controls } \\
n=263660\end{array}$ & $\begin{array}{l}\text { Stroke } \\
n=15950\end{array}$ & $\begin{aligned} \text { TIA } \\
n=10416\end{aligned}$ \\
\hline \multicolumn{5}{|l|}{ Primary } \\
\hline \multicolumn{5}{|c|}{$\begin{array}{l}\text { Death, admission for stroke or MI, admission } \\
\text { to CCC or LTC }\end{array}$} \\
\hline $1 \mathrm{yr}$ & $2496(9.5)$ & $14212(5.4)$ & $1758(11.0)$ & $738(7.1)$ \\
\hline $3 \mathrm{yr}$ & $5086(23.6)$ & $29229(13.6)$ & $3417(25.7)$ & $1669(20.2)$ \\
\hline $5 \mathrm{yr}$ & $5554(35.7)$ & $32797(21.1)$ & $3765(38.1)$ & $1789(31.5)$ \\
\hline \multicolumn{5}{|c|}{ Secondary } \\
\hline \multicolumn{5}{|l|}{ Stroke } \\
\hline $1 \mathrm{yr}$ & $670(2.5)$ & $1003(0.4)$ & $487(3.1)$ & $183(1.8)$ \\
\hline $3 \mathrm{yr}$ & $1173(5.4)$ & $2188(1.0)$ & $838(6.3)$ & $335(4.1)$ \\
\hline $5 \mathrm{yr}$ & $1221(7.8)$ & $2557(1.6)$ & $872(8.8)$ & $349(6.1)$ \\
\hline \multicolumn{5}{|l|}{ MI } \\
\hline $1 \mathrm{yr}$ & $262(1.0)$ & $1574(0.6)$ & $166(1.0)$ & $96(0.9)$ \\
\hline $3 \mathrm{yr}$ & $561(2.6)$ & $3405(1.6)$ & $350(2.6)$ & $211(2.6)$ \\
\hline $5 \mathrm{yr}$ & $601(3.9)$ & $3939(2.5)$ & $384(3.9)$ & $217(3.8)$ \\
\hline \multicolumn{5}{|c|}{ Admission to CCC or LTC } \\
\hline $1 \mathrm{yr}$ & $682(2.6)$ & $2623(1.0)$ & $500(3.1)$ & $182(1.7)$ \\
\hline $3 \mathrm{yr}$ & $1320(6.1)$ & $6156(2.9)$ & $878(6.6)$ & $442(5.4)$ \\
\hline $5 \mathrm{yr}$ & $1393(8.9)$ & $7312(4.7)$ & 949 (9.6) & $444(7.8)$ \\
\hline \multicolumn{5}{|l|}{ Death } \\
\hline $1 \mathrm{yr}$ & $1333(5.1)$ & 10809 (4.1) & $929(5.8)$ & 404 (3.9) \\
\hline $3 y r$ & 3372 (15.6) & $22773(10.6)$ & $2260(17.0)$ & $1112(13.5)$ \\
\hline $5 \mathrm{yr}$ & $4055(26.0)$ & $26287(16.9)$ & 2757 (27.9) & $1298(22.9)$ \\
\hline \multicolumn{5}{|c|}{$\begin{array}{l}\text { Note: } \mathrm{CCC}=\text { complex continuing care, } \mathrm{LTC}=\text { long-term care, } \mathrm{MI}=\text { myocardial infarction, } \mathrm{TIA}=\text { transient ischemic attack. } \\
{ }^{*} \text { For all comparisons (using } \chi^{2} \text { tests to compare cases and matched controls and to compare stroke and TIA subgroups), } p<0.001 \text {, except for } \\
\text { the comparison of stroke versus TIA subgroups for MI outcomes, where } p>0.05 \text { at all follow-up time points. } \\
\text { †The percentages for longitudinal analyses are based on the denominator of subcohorts with complete } 1-, 3 \text { - or } 5 \text {-year follow-up. The } \\
\text { denominator at } 1 \text { year was the same as the full cohort: } 26366 \text { total }(15950 \text { with stroke and } 10416 \text { with TIA). At } 3 \text { years, the subcohort } \\
\text { denominator was } 21548 \text { total ( } 13287 \text { with stroke and } 8261 \text { with TIA), and at } 5 \text { years the subcohort denominator was } 15571 \text { total (9894 with } \\
\text { stroke and } 5677 \text { with TIA). All matched control cohorts were matched } 10: 1 \text { with cases, so the denominator for the matched control cohort was } \\
10 \text { times the total denominator for each year: } 263660 \text { at } 1 \text { year, } 215480 \text { at } 3 \text { years and } 155710 \text { at } 5 \text { years. }\end{array}$} \\
\hline
\end{tabular}


reduce morbidity and admission to an institution after stroke or TIA. ${ }^{30}$

Although rates of adverse outcomes were significantly higher among patients with stroke than among those with TIA, subgroup analyses indicated that hazard ratios for the primary outcome and the majority of secondary outcomes in patients with TIA were also quite high. Specifically, almost one-third of patients with TIA experienced a primary outcome event within 5 years, with a 4 -fold increase in the hazard of recurrent stroke relative to controls for up to 5 years, which shows that even patients with transient presentations who have no early complications remain at increased risk of adverse outcomes over the long term. This finding is consistent with prior studies showing that 2-year stroke recurrence was similar among patients with minor compared with moderate or severe stroke or TIA ${ }^{31}$ and that patients with TIA and minor stroke had high cumulative long-term risks of both nonfatal and fatal myocardial infarction, ${ }^{32}$ confirming that longterm vascular risk can remain elevated, even for those with minor presenting events.

These high long-term risks were observed in the context of a universally funded and accessible health care system, with organized stroke services spanning the continuum of care. Canadian best practice recommendations for stroke have a strong focus on risk factor management for secondary stroke prevention, ${ }^{33}$ and the deployment of organized stroke services has resulted in significant improvements in both hospital and short-term outcomes, ${ }^{34,35}$ yet one gap that remains in organized outpatient care relates to long-term follow-up. Many secondary prevention clinics follow patients primarily during the highest-risk early phase (90 d after stroke or TIA), with the closest follow-up occurring for those with early adverse complications. Given the high total hospitalization costs associated with recurrent events, ${ }^{36}$ new models of secondary prevention may be required to bridge this gap in long-term care. Multifaceted programs for the use of evidence-based stroke prevention guidelines in the primary care setting are cost-effective and result in improved early treatment and preventive advice for individuals with TIA. ${ }^{37,38}$ There is also emerging evidence that primary care and community-based pharmacy interventions are effective in reducing the risk of cardiovascular outcomes. ${ }^{39,40}$ Thus, novel approaches to stroke prevention, potentially embedded in community or primary care, may be an effective alternative to specialty follow-up for long-term management in this high-risk population.

\section{Strengths and limitations}

An important strength of the present study was the use of a global population approach to identify a cohort of clinically stable patients with stroke and TIA most representative of patients who would be seen and discharged from specialist outpatient clinics. However, this study also had limitations. Information on stroke etiology was not available from the registry data. We were thus unable to identify potential differences in long-term risk associated with different mechanisms of the entry event. Given previously reported estimates for the sensitivity (80\%) and specificity (85\%-90\%) of stroke diagnoses, ${ }^{41}$ the present study was subject to potential biases due to misclassification or missing cases in the determination of stroke, as the entry event or the outcome event (or both).

Table 4: Hazard ratios at 1, 3 and 5 years for primary composite and secondary outcomes (cause-specific hazard models with robust standard errors for clustering in matched pairs)

\begin{tabular}{|c|c|c|c|c|c|c|c|c|c|}
\hline \multirow[b]{3}{*}{ Outcome } & \multicolumn{9}{|c|}{ Group; follow-up period; HR (95\% Cl) } \\
\hline & \multicolumn{3}{|c|}{ All cases } & \multicolumn{3}{|c|}{ Stroke only } & \multicolumn{3}{|c|}{ TIA only } \\
\hline & $1 \mathrm{yr}$ & $3 \mathrm{yr}$ & $5 \mathrm{yr}$ & $1 \mathrm{yr}$ & $3 \mathrm{yr}$ & $5 \mathrm{yr}$ & $1 \mathrm{yr}$ & $3 \mathrm{yr}$ & $5 \mathrm{yr}$ \\
\hline \multicolumn{10}{|l|}{ Primary } \\
\hline $\begin{array}{l}\text { Death, stroke or MI, } \\
\text { admission to CCC } \\
\text { or LTC }\end{array}$ & $\begin{array}{c}2.4 \\
(2.3-2.5)\end{array}$ & $\begin{array}{c}2.2 \\
(2.1-2.3)\end{array}$ & $\begin{array}{c}2.1 \\
(2.1-2.2)\end{array}$ & $\begin{array}{c}2.6 \\
(2.5-2.7)\end{array}$ & $\begin{array}{c}2.3 \\
(2.3-2.4)\end{array}$ & $\begin{array}{c}2.2 \\
(2.2-2.3)\end{array}$ & $\begin{array}{c}2.1 \\
(2.0-2.3)\end{array}$ & $\begin{array}{c}2.0 \\
(2.0-2.1)\end{array}$ & $\begin{array}{c}2.0 \\
(1.9-2.0)\end{array}$ \\
\hline \multicolumn{10}{|l|}{ Secondary* } \\
\hline Stroke & $\begin{array}{c}6.8 \\
(6.1-7.5)\end{array}$ & $\begin{array}{c}5.6 \\
(5.2-6.0)\end{array}$ & $\begin{array}{c}5.1 \\
(4.8-5.5)\end{array}$ & $\begin{array}{c}8.2 \\
(7.3-9.3)\end{array}$ & $\begin{array}{c}6.6 \\
(6.0-7.2)\end{array}$ & $\begin{array}{c}5.9 \\
(5.4-6.4)\end{array}$ & $\begin{array}{c}4.6 \\
(3.9-5.4)\end{array}$ & $\begin{array}{c}4.0 \\
(3.6-4.6)\end{array}$ & $\begin{array}{c}3.9 \\
(3.4-4.3)\end{array}$ \\
\hline MI & $\begin{array}{c}1.7 \\
(1.5-1.9)\end{array}$ & $\begin{array}{c}1.7 \\
(1.5-1.8)\end{array}$ & $\begin{array}{c}1.6 \\
(1.5-1.7)\end{array}$ & $\begin{array}{c}1.8 \\
(1.5-2.1)\end{array}$ & $\begin{array}{c}1.7 \\
(1.5-1.9)\end{array}$ & $\begin{array}{c}1.6 \\
(1.5-1.8)\end{array}$ & $\begin{array}{c}1.5 \\
(1.2-1.9)\end{array}$ & $\begin{array}{c}1.6 \\
(1.4-1.9)\end{array}$ & $\begin{array}{c}1.6 \\
(1.4-1.8)\end{array}$ \\
\hline $\begin{array}{l}\text { Admission to CCC } \\
\text { or LTC }\end{array}$ & $\begin{array}{c}2.6 \\
(2.4-2.9)\end{array}$ & $\begin{array}{c}2.2 \\
(2.1-2.4)\end{array}$ & $\begin{array}{c}2.1 \\
(1.9-2.2)\end{array}$ & $\begin{array}{c}3.3 \\
(3.0-3.7)\end{array}$ & $\begin{array}{c}2.5 \\
(2.3-2.7)\end{array}$ & $\begin{array}{c}2.3 \\
(2.1-2.4)\end{array}$ & $\begin{array}{c}1.7 \\
(1.4-2.0)\end{array}$ & $\begin{array}{c}1.8 \\
(1.7-2.0)\end{array}$ & $\begin{array}{c}1.7 \\
(1.6-1.9)\end{array}$ \\
\hline Death & $\begin{array}{c}1.2 \\
(1.2-1.3)\end{array}$ & $\begin{array}{c}1.5 \\
(1.5-1.6)\end{array}$ & $\begin{array}{c}1.6 \\
(1.6-1.7)\end{array}$ & $\begin{array}{c}1.4 \\
(1.3-1.5)\end{array}$ & $\begin{array}{c}1.7 \\
(1.6-1.7)\end{array}$ & $\begin{array}{c}1.8 \\
(1.7-1.8)\end{array}$ & $\begin{array}{c}0.9 \\
(0.8-1.0)\end{array}$ & $\begin{array}{c}1.3 \\
(1.2-1.3)\end{array}$ & $\begin{array}{c}1.4 \\
(1.3-1.5)\end{array}$ \\
\hline
\end{tabular}




\section{Conclusion}

Clinically stable patients, without any adverse complications in the first 90 days after stroke or TIA, had significantly elevated long-term hazards of death, stroke, myocardial infarction and admission to an institution, relative to matched controls, for at least 5 years. For survivors of stroke or TIA, the long-term risk of recurrent stroke was particularly high, indicating that stroke recurrence is the most important modifiable outcome and that aggressive long-term secondary prevention is warranted for risk reduction, even among survivors with no early complications. However, because most secondary stroke prevention clinics focus on the highest-risk early phase, novel system approaches to long-term management, embedded in community or primary care, may be required to address long-term risk for initially stable survivors of stroke and TIA.

\section{References}

1. Coull AJ, Lovett JK, Rothwell PM; Oxford Vascular Study. Population based study of early risk of stroke after transient ischaemic attack or minor stroke: implications for public education and organisation of services. BMJ 2004;328:326.

2. Hill MD, Yiannakoulias N, Jeerakathil T, et al. The high risk of stroke immediately after transient ischemic attack: a population-based study. Neurology 2004;62:2015-20.

3. Johnston SC, Gress DR, Browner WS, et al. Short-term prognosis after emergency department diagnosis of TIA. JAMA 2000;284:2901-6.

4. Lovett JK, Coull AJ, Rothwell PM. Early risk of recurrence by subtype of ischemic stroke in population-based incidence studies. Neurology 2004;62:569-73.

5. Giles MF, Rothwell PM. Risk of stroke early after transient ischaemic attack: a systematic review and meta-analysis. Lancet Neurol 2007;6:1063-72.

6. Touzé E, Varenne O, Chatellier G, et al. Risk of myocardial infarction and vascular death after transient ischemic attack and ischemic stroke: a systematic review and meta-analysis. Stroke 2005;36:2748-55.

7. Kernan WN, Ovbiagele B, Black HR, et al.; American Heart Association Stroke Council; Council on Cardiovascular and Stroke Nursing; Council on Clinical Cardiology; Council on Peripheral Vascular Disease. Guidelines for the prevention of stroke in patients with stroke and transient ischemic attack: a guideline for healthcare professionals from the American Heart Association/ American Stroke Association. Stroke 2014;45:2160-236.

8. Rothwell PM, Giles MF, Chandratheva A, et al.; Early use of Existing Preventive Strategies for Stroke (EXPRESS) study. Effect of urgent treatment of transient ischaemic attack and minor stroke on early recurrent stroke (EXPRESS study): a prospective population-based sequential comparison. Lancet 2007;370:1432-42.

9. Capoccia L, Sbarigia E, Speziale F, et al. Urgent carotid endarterectomy to prevent recurrence and improve neurologic outcome in mild-to-moderate acute neurologic events. J Vasc Surg 2011;53:622-7, discussion 627-8.

10. Dhamoon MS, Sciacca RR, Rundek T, et al. Recurrent stroke and cardiac risks after first ischemic stroke: the Northern Manhattan Study. Neurology 2006;66:641-6.

11. Hankey GJ, Jamrozik K, Broadhurst RJ, et al. Five-year survival after first-ever stroke and related prognostic factors in the Perth Community Stroke Study. Stroke 2000;31:2080-6.

12. Hardie K, Hankey GJ, Jamrozik K, et al. Ten-year risk of first recurrent stroke and disability after first-ever stroke in the Perth Community Stroke Study. Stroke 2004;35:731-5.

13. van Wijk I, Kappelle LJ, van Gijn J, et al.; LiLAC study group. Long-term survival and vascular event risk after transient ischaemic attack or minor ischaemic stroke: a cohort study. Lancet 2005;365:2098-104.
14. Clark TG, Murphy MF, Rothwell PM. Long term risks of stroke, myocardial infarction, and vascular death in "low risk" patients with a non-recent transient ischaemic attack. J Neurol Neurosurg Psychiatry 2003;74:577-80.

15. Hall R, Mondor L, Porter J, et al. Accuracy of administrative data for the coding of acute stroke and TIAs. Can J Neurol Sci 2016;43:765-73.

16. Data quality documentation, 2009-2010. Ottawa: Canadian Institute for Health Information; 2010. Available: www.cihi.ca/CIHI-ext-portal/pdf/internet/DAD_ EXECUTIVE_SUM_09_10_EN.pdf (accessed 2016 Jan. 26).

17. Data quality documentation, continuing care reporting system, 2014-2015. Ottawa: Canadian Institute for Health Information; 2015. Available: https:// secure.cihi.ca/free_products/CCRS-Data-Quality-Report-2014-2015_EN.pdf (accessed 2016 Jan. 26).

18. Vandenbroucke JP, von Elm E, Altman DG, et al. Strengthening the Reporting of Observational Studies in Epidemiology (STROBE): explanation and elaboration. PLoS Med 2007;4:e297.

19. Stavem K, Lossius M, Rønning OM. Reliability and validity of the Canadian Neurological Scale in retrospective assessment of initial stroke severity. Cerebrovasc Dis 2003;16:286-91.

20. PROGRESS Collaborative Group. Randomised trial of a perindopril-based blood-pressure-lowering regimen among 6,105 individuals with previous stroke or transient ischaemic attack. Lancet 2001;358:1033-41.

21. Gladstone DJ, Kapral MK, Fang J, et al. Management and outcomes of transient ischemic attacks in Ontario. CMAJ 2004;170:1099-104.

22. Lackland DT, Roccella EJ, Deutsch AF, et al.; American Heart Association Stroke Council; Council on Cardiovascular and Stroke Nursing; Council on Quality of Care and Outcomes Research; Council on Functional Genomics and Translational Biology. Factors influencing the decline in stroke mortality: a statement from the American Heart Association/American Stroke Association. Stroke 2014;45:315-53.

23. Edwards JD, Kapral M, Lindsay $\mathrm{P}$, et al. Temporal trends in mortality and morbidity in patients with no early complications after stroke and transient ischemic attack. J Stroke Cerebrovasc Dis. In press.

24. EAFT (European Atrial Fibrillation Trial) Study Group. Secondary prevention in non-rheumatic atrial fibrillation after transient ischaemic attack or minor stroke. Lancet 1993;342:1255-62.

25. Gladstone DJ, Spring M, Dorian P, et al.; EMBRACE Investigators and Coordinators. Atrial fibrillation in patients with cryptogenic stroke. N Engl J Med 2014;370:2467-77.

26. Swartz RH, Bayley M, Lanctôt KL, et al. Post-stroke depression, obstructive sleep apnea, and cognitive impairment: rationale for, and barriers to, routine screening. Int J Stroke 2016;11:509-18.

27. Luengo-Fernandez R, Paul NL, Gray AM, et al.; Oxford Vascular Study. Population-based study of disability and institutionalization after transient ischemic attack and stroke: 10-year results of the Oxford Vascular Study. Stroke 2013;44:2854-61.

28. Jørgensen HS, Nakayama H, Reith J, et al. Stroke recurrence: predictors, severity, and prognosis. The Copenhagen Stroke Study. Neurology 1997;48:891-5.

29. Hankey GJ, Jamrozik K, Broadhurst RJ, et al. Long-term disability after firstever stroke and related prognostic factors in the Perth Community Stroke Study, 1989-1990. Stroke 2002;33:1034-40.

30. Teasell RW, Foley NC, Salter KL, et al. A blueprint for transforming stroke rehabilitation care in Canada: the case for change. Arch Phys Med Rehabil 2008;89:575-8.

31. Coutts SB, Hill MD, Eliasziw M, et al.; VISION study group. Final 2 year results of the vascular imaging of acute stroke for identifying predictors of clinical outcome and recurrent ischemic eveNts (VISION) study. BMC CardiovasC Disord 2011;11:18.

32. Atanassova PA, Chalakova NT, Dimitrov BD. Major vascular events after transient ischaemic attack and minor ischaemic stroke: post hoc modelling of incidence dynamics. Cerebrovasc Dis 2008;25:225-33.

33. Coutts SB, Wein TH, Lindsay MP, et al.; Heart and Stroke Foundation of Canada Canadian Stroke Best Practices Advisory Committee. Canadian Stroke Best Practice Recommendations: secondary prevention of stroke guidelines, update 2014. Int J Stroke 2015;10:282-91. 
34. Saposnik G, Kapral MK, Coutts SB, et al.; Investigators of the Registry of the Canadian Stroke Network (RCSN) for the Stroke Outcome Research Canada (SORCan) Working Group. Do all age groups benefit from organized inpatient stroke care? Stroke 2009;40:3321-7.

35. Kapral MK, Fang J, Silver FL, et al. Effect of a provincial system of stroke care delivery on stroke care and outcomes. CMAJ 2013;185:E483-91.

36. Luengo-Fernandez R, Silver LE, Gutnikov SA, et al. Hospitalization resource use and costs before and after TIA and stroke: results from a population-based cohort study (OXVASC). Value Health 2013;16:280-7.

37. Wright J, Bibby J, Eastham J, et al. Multifaceted implementation of stroke prevention guidelines in primary care: cluster-randomised evaluation of clinical and cost effectiveness. Qual Saf Health Care 2007;16:51-9.
38. Wright J, Harrison S, McGeorge M, et al. Improving the management and referral of patients with transient ischaemic attacks: a change strategy for a health community. Qual Saf Health Care 2006;15:9-12.

39. Liu Z, Moorin R, Worthington J, et al. Using large-scale linkage data to evaluate the effectiveness of a national educational program on antithrombotic prescribing and associated stroke prevention in primary care. J Am Heart Assoc 2016;5:e003729.

40. Tsuyuki RT, Al Hamarneh YN, Jones CA, et al. The effectiveness of pharmacist interventions on cardiovascular risk: the multicenter randomized controlled RxEACH trial. J Am Coll Cardiol 2016;67:2846-54.

41. Kokotailo RA, Hill MD. Coding of stroke and stroke risk factors using international classification of diseases, revisions 9 and 10. Stroke 2005;36:1776-81.

\section{Competing interests: None declared.}

This article has been peer reviewed.

Affiliations: Sunnybrook Research Institute (Edwards, Swartz), Toronto, Ont.; Canadian Partnership for Stroke Recovery (Edwards), Ottawa, Ont.; Department of Medicine, Division of General Internal Medicine (Kapral), Institute of Health Policy, Management and Evaluation (Kapral), and Department of Medicine, Neurology (Swartz), University of Toronto; Institute for Clinical Evaluative Sciences (Kapral, Fang), Toronto, Ont.

Contributors: Richard Swartz was responsible for the study concept and funding. Richard Swartz, Jodi Edwards and Moira Kapral were responsible for study design and developed the analytic plan, and Jiming Fang was respon- sible for all data analysis. Jodi Edwards and Richard Swartz were responsible for manuscript preparation, and Richard Swartz, Moira Kapral and Jiming Fang were responsible for critical review and revision of the manuscript. All of the authors approved the final version for publication and agreed to act as guarantors of the work.

Funding: This study was supported by the Institute for Clinical and Evaluative Sciences (ICES), which is funded by an annual grant from the Ontario Ministry of Health and LongTerm Care (MOHLTC). Parts of this material are based on data and/or information compiled and provided by the Canadian Institute for Health Information (CIHI). Jodi Edwards holds a Post-Doctoral Fellowship Award from the Heart and Stroke Foundation (HSF) of Canada,
Richard Swartz holds a New Investigator Award from HSF Canada, and Moira Kapral holds a Career Investigator Award from HSF, Ontario Provincial Office. The opinions, results and conclusions reported in this paper are those of the authors, are independent from the funding sources and do not necessarily reflect those of $\mathrm{CIHI}$. No endorsement by ICES, the Ontario MOHLTC or $\mathrm{CIHI}$ is intended or should be inferred.

Acknowledgement: The authors gratefully acknowledge the valuable feedback of Dr. Michael Hill for this manuscript.

Accepted: Mar. 6, 2017

Correspondence to: Richard Swartz, rick. swartz@sunnybrook.ca 